\title{
Meningeal Tuberculosis
}

National Cancer Institute

\section{Source}

National Cancer Institute. Meningeal Tuberculosis. NCI Thesaurus. Code C84888.

A bacterial infection of the membranes covering the brain and the spinal cord caused by Mycobacterium tuberculosis. 